\title{
Female-dominant estrogen production in healthy children before adrenarche
}

\author{
Maki Igarashi ${ }^{1,2, *, \dagger}$, Tadayuki Ayabe ${ }^{1,2,{ }^{*},}$, Kiwako Yamamoto-Hanada ${ }^{1}$, Keiko Matsubara $^{2}$, Hatoko Sasaki ${ }^{1}$, \\ Mayako Saito-Abe', Miori Sato ${ }^{1}$, Nathan Mise ${ }^{3}$, Akihiko Ikegami ${ }^{3}$, Masayuki Shimono ${ }^{4}$, Reiko Suga ${ }^{4}$, \\ Shouichi Ohga ${ }^{5,6}$, Masafumi Sanefuji5,6, Masako Oda ${ }^{7}$, Hiroshi Mitsubuchi ${ }^{8}$, Takehiro Michikawa ${ }^{9}$, Shin Yamazaki ${ }^{9}$, \\ Shoji Nakayama ${ }^{9}$, Yukihiro Ohya ${ }^{1}$ and Maki Fukami ${ }^{1,2}$

\begin{abstract}
${ }^{1}$ Medical Support Center for Japan Environmental and Children's Study, National Center for Child Health and Development, Setagaya, Tokyo, Japan ${ }^{2}$ Department of Molecular Endocrinology, National Research Institute for Child Health and Development, Setagaya, Tokyo, Japan ${ }^{3}$ Department of Environmental and Preventive Medicine, Jichi Medical University, Shimotsuke, Tochigi, Japan

${ }^{4}$ Regional Center for Pilot Study of Japan Environment and Children's Study, School of Medicine, University of Occupational and Environmental Health, Kitakyushu, Fukuoka, Japan

${ }^{5}$ Department of Pediatrics, Graduate School of Medical Sciences, Kyushu University, Higashi-ku, Fukuoka, Japan

${ }^{6}$ Research Center for Environment and Developmental Medical Sciences, Kyushu University, Higashi-ku, Fukuoka, Japan

${ }^{7}$ Department of Public Health, Faculty of Life Sciences, Kumamoto University, Chuo-ku, Kumamoto, Japan

${ }^{8}$ Department of Neonatology, Kumamoto University Hospital, Chuo-ku, Kumamoto, Japan
\end{abstract} \\ 9 Japan Environment and Children's Study Programme Office, National Institute for Environmental Studies, Tsukuba, Ibaraki, Japan
}

Correspondence should be addressed to M Fukami: fukami-m@ncchd.go.jp

*(M Igarashi and T Ayabe contributed equally to this work)

${ }^{\dagger}$ (M Igarashi is now at Laboratory of Health Nutrition, Department of Applied Biological Chemistry, Graduate School of Agricultural and Life Sciences, The University of Tokyo, Tokyo, Japan)

\begin{abstract}
Objective: Ultra-sensitive hormone assays have detected slight sex differences in blood estradiol $\left(E_{2}\right)$ levels in young children before adrenarche. However, the origin of circulating $E_{2}$ in these individuals remains unknown. This study aimed to clarify how $E_{2}$ is produced in young girls before adrenarche.

Design: This is a satellite project of the Japan Environment and Children's Study organized by the National Institute for Environmental Studies.

Methods: We collected blood samples from healthy 6-year-old Japanese children (79 boys and 71 girls). Hormone measurements and data analysis were performed in the National Institute for Environmental Studies and the Medical Support Center of the Japan Environment and Children's Study, respectively. Results: $\mathrm{E}_{2}$ and follicle stimulating hormone (FSH) levels were significantly higher in girls than in boys, while dehydroepiandrosterone sulfate (DHEA-S) and testosterone levels were comparable between the two groups. Girls showed significantly higher

$\mathrm{E}_{2}$ /testosterone ratios than boys. In children of both sexes, a correlation was observed between $\mathrm{E}_{2}$ and testosterone levels and between testosterone and DHEA-S levels.

Moreover, $\mathrm{E}_{2}$ levels were correlated with FSH levels only in girls.

Conclusions: The results indicate that in 6-year-old girls, circulating $\mathrm{E}_{2}$ is produced primarily in the ovary from adrenal steroids through $\mathrm{FSH}$-induced aromatase upregulation. This study provides evidence that female-dominant $\mathrm{E}_{2}$ production starts several months or years before adrenarche. The biological significance of $E_{2}$ biosynthesis in these young children needs to be clarified in future studies.
\end{abstract}

\author{
Key Words \\ - puberty \\ - paediatric endocrinology
}

https://ec.bioscientifica.com

https://doi.org/10.1530/EC-21-0134 (c) 2021 The authors Published by Bioscientifica Ltd

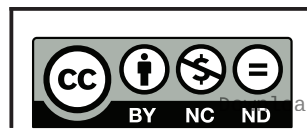

This work is licensed under a Creative Commons Attribution-NonCommercial-NoDerivatives 4.0 Internationab ticense.ifica.com at 04/26/2023 09:01:32AM
Endocrine Connections (2021) 10, 1221-1226 


\section{Introduction}

The first physical signs of puberty in boys and girls are testicular enlargement and breast budding, respectively (1). Typically, these signs appear at 11-12 years of age in boys and at 9-10 years of age in girls (1). Several years before developing physical signs, children undergo conspicuous changes in the blood levels of sex hormones. Usually, an increase in circulating adrenal steroids ('adrenarche') occurs at 7 or 8 years of age in children of both sexes (1, $2,3)$. Subsequently, an increase in circulating gonadal steroids ('gonadarche') takes place in a sex-specific manner. In girls, blood levels of estradiol $\left(\mathrm{E}_{2}\right)$ start to increase around 8 years of age, while in boys, testosterone levels typically increase at 9 years of age or later $(1,4,5,6)$. Thus, sexual dimorphism in blood sex hormone levels is evident in children above 8 years of age. Furthermore, ultra-sensitive hormone assays using liquid chromatography-tandem mass spectrometry (LC-MS/MS) have revealed slight sex differences in circulating $\mathrm{E}_{2}$ levels in children below 7 years of age (6). These results indicate that sex-specific hormone production begins before adrenarche. However, given the limited number of previous reports, these data require further validation. Moreover, this notion raises a fundamental question of how $\mathrm{E}_{2}$ is produced in young girls before adrenarche. To clarify the origin of circulating $\mathrm{E}_{2}$ in young girls, we measured serum levels of sex hormones and gonadotropins in 150 healthy children at 6 years of age.

\section{Materials and methods}

\section{Subjects}

This project was conducted in the framework of a pilot study of the Japan Environment and Children's Study (JECS). JECS is a large-scale birth cohort study of the Japan Ministry of the Environment, which is organized by the National Institute for Environmental Studies. The participants of the present study were recruited during a JECS pilot study targeting 6-year-old children. The present study was approved by the ethics committee of the National Institute for Environmental Studies and that of four JECS pilot study-centers. This study was carried out in accordance with the Declaration of Helsinki. Written informed consent was obtained from the participants' parents or guardians.

The participants of this study consisted of 79 boys and 71 girls aged at 5.75-6.58 years (Supplementary Table 1, see section on supplementary materials given at the end of this article). These children were recruited from four
JECS pilot study-centers. All children were apparently healthy and exhibited no physical signs of puberty. The age, height, and body weight were comparable between the boy and girl groups (Table 1). Blood samples were obtained either in the morning (42 boys and 36 girls) or afternoon (30 boys and 30 girls), while information about the sampling time was unavailable for seven boys and five girls.

\section{Hormone measurements}

Serum levels of $E_{2}$, testosterone, and dehydroepiandrosterone sulfate (DHEA-S) were measured using LC-MS/MS (LSI Medience, Tokyo, Japan). The methods were described previously (7). The lower detection limits of $\mathrm{E}_{2}$, testosterone, and DHEA-S were $0.092 \mathrm{pmol} / \mathrm{L}$ $(0.025 \mathrm{pg} / \mathrm{mL}), 0.017 \mathrm{nmol} / \mathrm{L}(5 \mathrm{pg} / \mathrm{mL})$, and $0.14 \mu \mathrm{mol} / \mathrm{L}$ $(50 \mathrm{pg} / \mathrm{mL})$, respectively. Serum levels of luteinizing hormone (LH) and follicle stimulating hormone (FSH) were measured using standard chemiluminescent enzyme immune assays (LSI Medience). The lower detection limits of LH and FSH were both $0.1 \mathrm{IU} / \mathrm{L}$. We calculated blood $\mathrm{E}_{2} /$ testosterone ratios, which reflect the enzymatic activity of aromatase (8).

\section{Statistical analysis}

Sex differences in the hormone values and $\mathrm{E}_{2} /$ testosterone ratios were analyzed by the Wilcoxon rank sum test. Differences in hormone levels between samples obtained in the morning and afternoon were analyzed using the Wilcoxon signed rank test. Correlations between two hormone values were analyzed by the Spearman rank correlation test and the relationship between $\mathrm{E} 2$ and other sex hormones were examined by linear regression analysis. All statistical analyses were performed using $\mathrm{R}$ (version 4.0.0, R Core Team, Vienna, Austria). $P$-values of less than 0.05 were considered significant.

Table 1 Clinical data of the participants. Data are presented as the median (range).

\begin{tabular}{|c|c|c|c|}
\hline & Boys & Girls & P-value \\
\hline Number & 79 & 71 & \\
\hline Age (years) & $6.00(5.83-6.58)$ & $6.00(5.75-6.50)$ & 0.63 \\
\hline Height (cm) & $114.2(101.8-124.7)$ & $113.5(101.6-127.9)$ & 0.73 \\
\hline $\begin{array}{l}\text { Body } \\
\text { weight (kg) }\end{array}$ & $20.4(14.4-35.1)$ & $19.0(13.9-27.7)$ & 0.12 \\
\hline
\end{tabular}

This work is licensed under a Creative Commons Attribution-NonCommercial-NoDerivatives 4.0 internationab dicense.ifica.com at 04/26/2023 09:01:32AM 


\section{Results}

\section{Blood hormone levels}

The results of the 150 children are shown in Fig. 1 and Supplementary Table 1 . In most children, serum levels of LH were undetectable, while levels of testosterone, $\mathrm{E}_{2}$, DHEA-S, and FSH were low but above the detection limit. Thus, LH was excluded from statistical analyses.

\section{Sex differences in blood hormone levels and $\mathrm{E}_{2}$ /testosterone ratios}

Blood levels of $\mathrm{E}_{2}$ and FSH were significantly higher in the girl group than in the boy group, whereas levels of DHEA-S and testosterone were comparable between the two groups (Fig. 1). Consequently, $\mathrm{E}_{2} /$ testosterone ratios were significantly higher in the girl group than in the boy group.

Blood samples obtained in the morning and afternoon contained almost equal levels of hormones, except for testosterone and $\mathrm{E}_{2}$ (Supplementary Table 2). Testosterone levels in the boy and girl groups and $\mathrm{E}_{2}$ levels in the boy group were relatively high in the samples obtained in the morning. However, the differences between samples obtained in the morning and afternoon were small.

In children of both sexes, serum $\mathrm{E}_{2}$ levels were positively correlated with testosterone levels, and testosterone levels were correlated with DHEA-S levels (Table 2). Furthermore, $\mathrm{E}_{2}$ levels were positively correlated with FSH levels in girls, but not in boys. Likewise, linear regression analysis revealed that $\mathrm{E}_{2}$ levels was associated with testosterone and FSH levels only in girls (Table 3).

\section{Discussion}

We measured serum levels of sex hormones and gonadotropins in 150 healthy children at 6 years of age. In most children, levels of $\mathrm{E}_{2}$, testosterone, DHEA-S, and FSH were above the detection limit, while LH levels remained extremely low. Blood levels of DHEA-S and testosterone in these children were lower than the levels previously documented for children during adrenarche (9, 10), indicating that our participants had not yet entered adrenarche. These results are consistent with the report by Tung et al. that the average age of adrenarche in the East
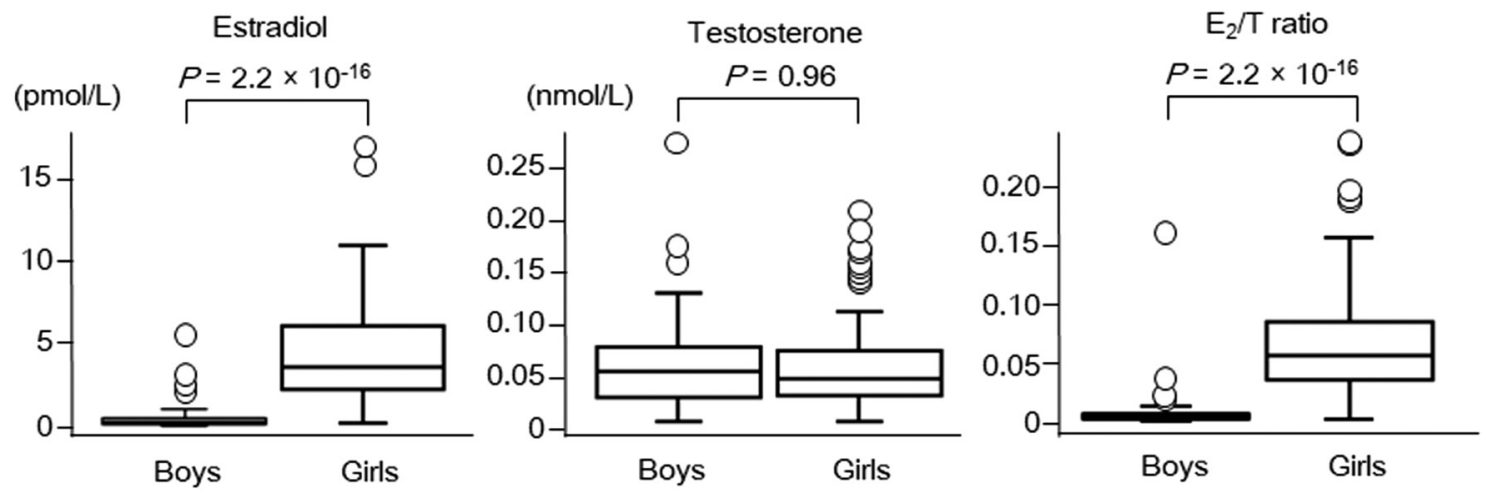

Dehydroepiandrosterone sulfate

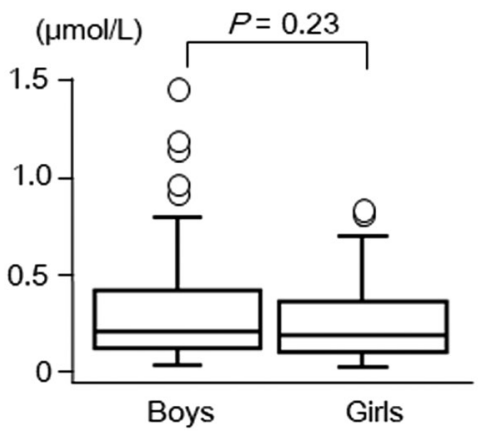

Follicle stimulating hormone

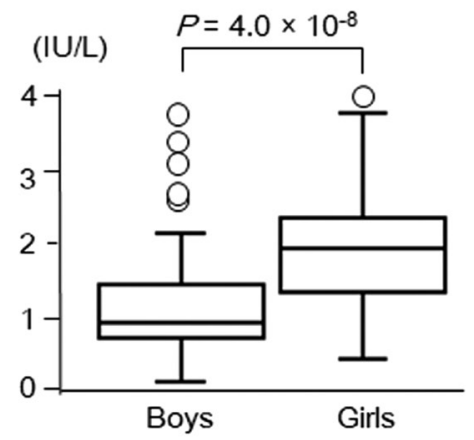

Figure 1

Blood hormone levels and estradiol/testosterone $\left(E_{2} / T\right)$ ratios in boys and girls. The upper and lower borders of each box indicate the 75 th and 25 th percentiles, respectively. Thick horizontal lines represent the median; upper whisker ends, 75th percentile plus 1.5 interquartile range (IQR); and lower whisker ends, 25th percentile minus 1.5 IQR. The values that exceed indicated ranges are plotted as individual circles. 
Table 2 Correlation between two hormone values.

\begin{tabular}{|c|c|c|c|c|c|}
\hline & & \multicolumn{4}{|c|}{ P-value } \\
\hline & & $\mathrm{E}_{2}$ & DHEA-S & Testosterone & $\mathrm{FSH}$ \\
\hline \multicolumn{6}{|c|}{ Boys } \\
\hline \multirow[t]{4}{*}{ r } & $\mathrm{E}_{2}$ & & $3.12 \times 10^{-15}$ & $1.59 \times 10^{-11}$ & 0.81 \\
\hline & DHEA-S & 0.75 & & $1.04 \times 10^{-13}$ & 0.70 \\
\hline & Testosterone & 0.67 & 0.72 & & 0.14 \\
\hline & $\mathrm{FSH}$ & 0.03 & 0.04 & 0.17 & \\
\hline \multicolumn{6}{|c|}{ Girls } \\
\hline \multirow[t]{4}{*}{$r$} & $\mathrm{E}_{2}$ & & 0.19 & $6.12 \times 10^{-4}$ & $3.09 \times 10^{-3}$ \\
\hline & DHEA-S & 0.16 & & $5.57 \times 10^{-10}$ & 0.40 \\
\hline & Testosterone & 0.40 & 0.66 & & 0.88 \\
\hline & $\mathrm{FSH}$ & 0.35 & -0.10 & 0.02 & \\
\hline
\end{tabular}

$\mathrm{E}_{2}$, estradiol; DHEA-S, dehydroepiandrosterone sulfate; $\mathrm{FSH}$, follicle stimulating hormone.

Asian population is 7.7 years (3). Nevertheless, we found a significant difference in serum $\mathrm{E}_{2}$ levels between boys and girls. This sexual dimorphism in circulating $\mathrm{E}_{2}$ levels cannot be ascribed to the female-dominant $\mathrm{E}_{2}$ production in the adrenal gland, because serum levels of DHEA-S, a marker for adrenal steroidogenesis $(2,11)$, were comparable between the boy and girl groups. Instead, a significant sex difference was observed in the $\mathrm{E}_{2} /$ testosterone ratios. These results indicate that in healthy children, female-dominant aromatase activation precedes adrenarche. This notion provides an answer to the previously raised question of why serum testosterone levels of a girl with congenital aromatase deficiency remained within the normal range until 5 years of age and became abnormally high thereafter (12). Notably, we found a slight difference in testosterone levels between samples obtained in the morning and afternoon. These results are consistent with the previous findings that there is a diurnal rhythm of testosterone secretion in both prepubertal and pubertal children $(10,13)$.

In children of both sexes, serum levels of $\mathrm{E}_{2}$ were correlated with testosterone levels, which inturn were correlated with DHEA-S levels. These results imply that circulating $\mathrm{E}_{2}$ in these children was synthesized primarily from adrenal steroids through the intermediacy of testosterone. We speculate that the conversion of testosterone to $\mathrm{E}_{2}$ in girls occurs mostly in the ovary, because (i) CYP19A1, the gene encoding aromatase, is strongly expressed in the ovary $(8,14)$, (ii) blood $\mathrm{E}_{2}$ levels in our female participants were higher than those in previously reported girls and young adults with pure ovarian dysgenesis $(2.41 \pm 1.67 \mathrm{pmol} / \mathrm{L})$ (15), and (iii) Wilson et al. observed an increase in blood $\mathrm{E}_{2}$ levels in healthy prepubertal girls at 5-12 years of age but not in age-matched girls with ovarian dysfunction due to Turner syndrome (16). However, it is possible that other CYP19A1expressing tissues, such as the skin, adipose tissues, and bone (8) also contribute to the aromatization of circulating testosterone in young girls.

FSH levels were slightly higher in girls than in boys. Female-dominant FSH secretion in prepubertal children has been documented in previous reports $(4,17)$ and is likely to reflect sex-specific hypothalamic function that governs gonadotropin secretion (1). Notably, serum FSH levels were positively correlated with $\mathrm{E}_{2}$ levels only in girls. These results indicate that in girls, $\mathrm{FSH}$ upregulates CYP19A1 in the ovary to facilitate $\mathrm{E}_{2}$ production. Indeed, $\mathrm{FSH}$ is known to stimulate CYP19A1 expression in the ovary (18). Moreover, Francois et al. have shown that in normal infant mice, FSH induces $\mathrm{E}_{2}$ production in the ovary without causing follicular growth (19). Interestingly, the authors proposed that $\mathrm{E}_{2}$ production in the immature murine ovary is indispensable for the programming of future reproductive function. Thus, the relatively small increase in serum $\mathrm{E}_{2}$ levels observed in our female participants may also be essential for ovarian function in later life. In contrast, LH is unlikely to contribute to the female-dominant $\mathrm{E}_{2}$ production in young children, because serum levels of $\mathrm{LH}$ remained undetectable in most of our participants.

Table 3 Multiple linear regression model with estradiol as the outcome variable.

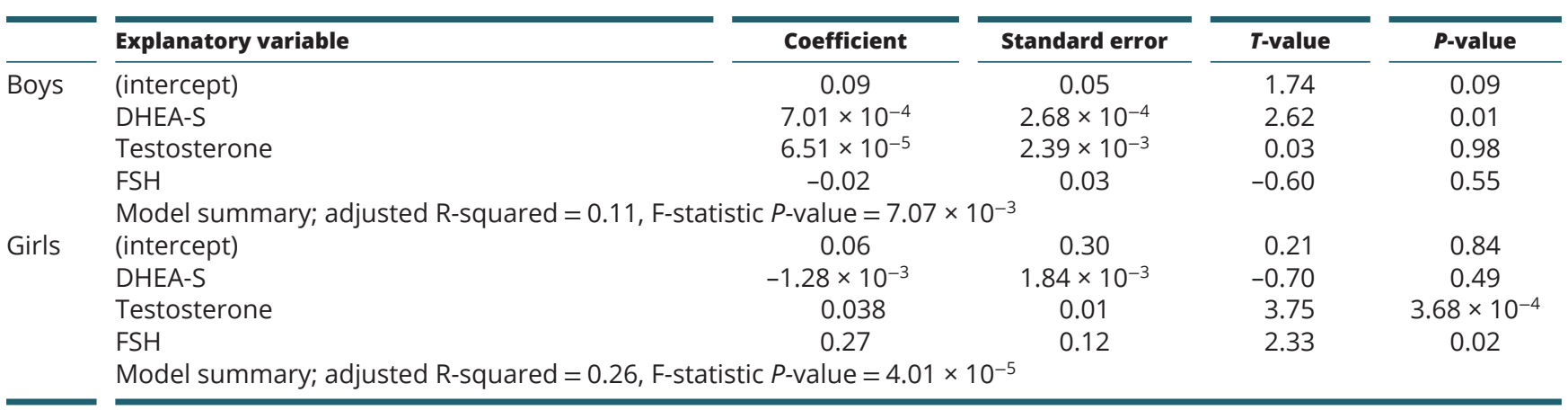

DHEA-S, dehydroepiandrosterone sulfate; FSH, follicle-stimulating hormone.

https://ec.bioscientifica.com https://doi.org/10.1530/EC-21-0134 (c) 2021 The authors
Published by Bioscientifica Ltd

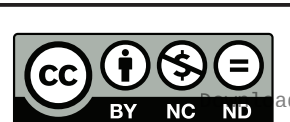

This work is licensed under a Creative Commons Attribution-NonCommercial-NoDerivatives 4.0 elnternationab ficense.ifica com at 04/26/2023 09:01:32AM 
This study has several limitations. First, this is a cross-sectional study. Thus, we could not determine the onset age of female-dominant $\mathrm{E}_{2}$ production. Since previous studies have shown that blood FSH levels are constantly higher in girls than in boys from infancy through adolescence (4), there may be a sex difference in aromatase activity even in children under 6 years of age. Second, we did not measure levels of sex hormone binding globulin. Blood levels of total fractions of sex hormones may not be parallel with the levels of unbound (free and bioavailable) hormones (20). Third, our conclusions are based solely on the results of blood hormone measurement. Venous sampling is useful to determine the tissue origin of circulating sex hormones in children, although this test is generally not feasible in humans. Lastly, we did not address the functional importance of $\mathrm{E}_{2}$ production in young girls. Further studies are necessary to clarify whether sex hormone production in childhood is associated with sexual maturation during puberty or reproductive function in adulthood.

In conclusion, the results show that sexual dimorphism in sex hormone production is already apparent in 6-year-old children. Excessive circulating $\mathrm{E}_{2}$ in these girls is most likely synthesized in the ovary from adrenal steroids through FSH-induced aromatase upregulation. The biological significance of $\mathrm{E}_{2}$ production in such young children needs to be clarified in future studies.

\section{Supplementary materials}

This is linked to the online version of the paper at https://doi.org/10.1530/ EC-21-0134.

\section{Declaration of interest}

The authors declare that there is no conflict of interest that could be perceived as prejudicing the impartiality of the research reported.

\section{Funding}

This study was funded by the National Institute for Environmental Studies. The findings and conclusions of this article are solely the responsibility of the authors and do not represent the official views of the aforementioned institute. This study was also supported by a grant from the Japan Society for the Promotion of Science (17H06428).

\section{References}

1 Styne DM. Physiology and disorders of puberty. In Williams Textbook of Endocrinology, 14th ed., pp. 1023-1194. Eds S Melmed, RJ Auchus, AB Goldfine, RJ Koenig \& CJ Rosen. Pennsylvania: Elsevier, 2020.

2 Auchus RJ \& Rainey WE. Adrenarche: physiology, biochemistry and human disease. Clinical Endocrinology 200460 288-296. (https://doi. org/10.1046/j.1365-2265.2003.01858.x)
3 Tung YC, Lee JS, Tsai WY \& Hsiao PH. Physiological changes of adrenal androgens in childhood. Journal of the Formosan Medical Association 2004103 921-924.

4 Zec I, Kučak I, Begčević I, Simundić AM, Tišlarić-Medenjak D, Megla ZB \& Vrkić N. Reference intervals for reproductive hormones in prepubertal children on the automated Roche cobase 411 analyzer. Clinical Biochemistry 201245 1206-1212. (https://doi.org/10.1016/j. clinbiochem.2012.05.019)

5 Kushnir MM, Blamires T, Rockwood AL, Roberts WL, Yue B, Erdogan E, Bunker AM \& Meikle AW. Liquid chromatography-tandem mass spectrometry assay for androstenedione, dehydroepiandrosterone, and testosterone with pediatric and adult reference intervals. Clinical Chemistry 201056 1138-1147. (https://doi.org/10.1373/ clinchem.2010.143222)

6 Frederiksen H, Johannsen TH, Andersen SE, Albrethsen J, Landersoe SK, Petersen JH, Andersen AN, Vestergaard ET, Schorring ME, Linneberg A, et al. Sex-specific estrogen levels and reference intervals from infancy to late adulthood determined by LC-MS/MS. Journal of Clinical Endocrinology and Metabolism 2020105 754-768. (https://doi.org/10.1210/clinem/dgz196)

7 Saito K, Matsuzaki T, Iwasa T, Miyado M, Saito H, Hasegawa T, Homma K, Inoue E, Miyashiro Y, Kubota T, et al. Steroidogenic pathways involved in androgen biosynthesis in eumenorrheic women and patients with polycystic ovary syndrome. Journal of Steroid Biochemistry and Molecular Biology 2016158 31-37. (https://doi. org/10.1016/j.jsbmb.2016.02.010)

8 Miller WL \& Auchus RJ. The molecular biology, biochemistry, and physiology of human steroidogenesis and its disorders. Endocrine Reviews 201132 81-151. (https://doi.org/10.1210/er.2010-0013)

9 Ankarberg-Lindgren C, Dahlgren J \& Andersson MX. Highsensitivity quantification of serum androstenedione, testosterone, dihydrotestosterone, estrone and estradiol by gas chromatographytandem mass spectrometry with sex- and puberty-specific reference intervals. Journal of Steroid Biochemistry and Molecular Biology 2018183 116-124. (https://doi.org/10.1016/j.jsbmb.2018.06.005)

10 Ankarberg C \& Norjavaara E. Diurnal rhythm of testosterone secretion before and throughout puberty in healthy girls: correlation with 17beta-estradiol and dehydroepiandrosterone sulfate. Journal of Clinical Endocrinology and Metabolism 199984 975-984. (https://doi. org/10.1210/jcem.84.3.5524)

11 Witchel SF, Pinto B, Burghard AC \& Oberfield SE. Update on adrenarche. Current Opinion in Pediatrics 202032 574-581. (https://doi. org/10.1097/MOP.0000000000000928)

12 Constanzo M, Garcia-Feyling J, Saraco N, Marino R, Pérez Garrido N, Touzon MS, Viterbo G, Lazzati JM, Patiño HC, Mattone C, et al. Accelerated pubertal tempo in a 46,XY aromatase-deficient patient. Hormone Research in Paediatrics 201890 275-282. (https://doi. org/10.1159/000492128)

13 Ankarberg-Lindgren C \& Norjavaara E. Twenty-four hours secretion pattern of serum estradiol in healthy prepubertal and pubertal boys as determined by a validated ultra-sensitive extraction RIA. BMC Endocrine Disorders 20088 10. (https://doi.org/10.1186/1472-6823-8-10)

14 Stocco C. Aromatase expression in the ovary: hormonal and molecular regulation. Steroids 200873 473-487. (https://doi.org/10.1016/j. steroids.2008.01.017)

15 Huang H, Wang CQ \& Tian QJ. Clinical features and management of 33 patients with 46,XX pure gonadal dysgenesis. Gynecological Endocrinology 201632 995-998. (https://doi.org/10.1080/09513590.201 6.1190820)

16 Wilson CA, Heinrichs C, Larmore KA, Craen M, Brown-Dawson J, Shaywitz S, Ross J \& Klein KO. Estradiol levels in girls with Turner's syndrome compared to normal prepubertal girls as determined by an ultrasensitive assay. Journal of Pediatric Endocrinology and Metabolism 2003 16 91-96. (https://doi.org/10.1515/jpem.2003.16.1.91)

17 Neely EK, Hintz RL, Wilson DM, Lee PA, Gautier T, Argente J \& Stene M. Normal ranges for immunochemiluminometric 
gonadotropin assays. Journal of Pediatrics 1995127 40-46. (https://doi. org/10.1016/s0022-3476(95)70254-7)

18 Hobeika E, Armouti M, Kala H, Fierro MA, Winston NJ, Scoccia B, Zamah AM \& Stocco C. Oocyte-secreted factors synergize with FSH to promote aromatase expression in primary human cumulus cells. Journal of Clinical Endocrinology and Metabolism 2019104 1667-1676. (https://doi.org/10.1210/jc.201801705)
19 François CM, Petit F, Giton F, Gougeon A, Ravel C, Magre S, CohenTannoudji J \& Guigon CJ. A novel action of follicle-stimulating hormone in the ovary promotes estradiol production without inducing excessive follicular growth before puberty. Scientific Reports 20177 46222. (https://doi.org/10.1038/srep46222)

20 Selby C. Sex hormone binding globulin: origin, function and clinical significance. Annals of Clinical Biochemistry 199027 532-541. (https:// doi.org/10.1177/000456329002700603)

Received in final form 17 August 2021

Accepted 1 September 2021

Accepted Manuscript published online 1 September 2021 (c) 2021 The authors Published by Bioscientifica Ltd
This work is licensed under a Creative Commons Attribution-NonCommercial-NoDerivatives 4.0 enternationad dicense ifica. com at 04/26/2023 09:01:32AM 